\title{
Designing the Information Space and Physical Layout for a Command Center Based on an Optimized Organizational Structure
}

\author{
Jean MacMillan* \\ Michael J. Paley \\ Yuri N. Levchuk \\ Daniel Serfaty \\ Aptima, Inc. \\ 600 West Cummings Park, Suite 3050 \\ Woburn, MA 01801 \\ Phone: (781) 935-3966 \\ Fax: (781) 935-4385 \\ Email: aptima@aptima.com
}

\begin{abstract}
This paper presents a method for designing the physical layout of a command center to best support team performance, based on the communication and information structure of the team. The command center design method is based on an optimized team design model that produces the best team structure for a specific mission. Using information about the team's communication patterns and information needs, we apply model-based principles to evaluate candidate designs for the physical layout of the command center and to develop designs best suited to the team structure.
\end{abstract}

\section{Introduction}

The information infrastructure and physical layout of command centers often evolve in a somewhat ad hoc fashion as new technologies are added, new positions created, and new connections and communication links are established within and between command nodes. The problem is especially acute for shipboard command centers like the Combat Information Center (CIC) aboard the Navy's AEGIS ships. Equipment acquisition for the CIC often has been "stovepiped," with each new system or capability developed in isolation from all others, and with little consideration given to the existing CIC team organization or how the new capability will best fit into the existing structure. With each new technology, a new, dedicated team member must be added to operate the new system, and the new equipment and new watchstanders must be fitted into the limited space wherever possible.

\footnotetext{
* This work was prepared for the Manning Affordability Initiative under the sponsorship of the Naval Air Warfare Center, Training Systems Division.
} 


\section{Report Documentation Page}

Form Approved

OMB No. 0704-0188

Public reporting burden for the collection of information is estimated to average 1 hour per response, including the time for reviewing instructions, searching existing data sources, gathering and maintaining the data needed, and completing and reviewing the collection of information. Send comments regarding this burden estimate or any other aspect of this collection of information,

including suggestions for reducing this burden, to Washington Headquarters Services, Directorate for Information Operations and Reports, 1215 Jefferson Davis Highway, Suite 1204, Arlington

VA 22202-4302. Respondents should be aware that notwithstanding any other provision of law, no person shall be subject to a penalty for failing to comply with a collection of information if it

does not display a currently valid OMB control number.

\begin{tabular}{|c|c|}
\hline $\begin{array}{l}\text { 1. REPORT DATE } \\
\mathbf{1 9 9 9}\end{array}$ & $\begin{array}{l}\text { 3. DATES COVERED } \\
\text { 00-00-1999 to 00-00-1999 }\end{array}$ \\
\hline \multirow{3}{*}{$\begin{array}{l}\text { Designing the Information Space and Physical Layout for a Command } \\
\text { Center Based on an Optimized Organizational Structure }\end{array}$} & 5a. CONTRACT NUMBER \\
\hline & 5b. GRANT NUMBER \\
\hline & 5c. PROGRAM ELEMENT NUMBER \\
\hline \multirow[t]{3}{*}{ 6. AUTHOR(S) } & 5d. PROJECT NUMBER \\
\hline & 5e. TASK NUMBER \\
\hline & 5f. WORK UNIT NUMBER \\
\hline $\begin{array}{l}\text { 7. PERFORMING ORGANIZATION NAME(S) AND ADDRESS(ES) } \\
\text { Aptima Inc,600 West Cummings Park Suite 3050,Woburn,MA,01801 }\end{array}$ & $\begin{array}{l}\text { 8. PERFORMING ORGANIZATION } \\
\text { REPORT NUMBER }\end{array}$ \\
\hline \multirow[t]{2}{*}{ 9. SPONSORING/MONITORING AGENCY NAME(S) AND ADDRESS(ES) } & 10. SPONSOR/MONITOR'S ACRONYM(S) \\
\hline & $\begin{array}{l}\text { 11. SPONSOR/MONITOR'S REPORT } \\
\text { NUMBER(S) }\end{array}$ \\
\hline
\end{tabular}

12. DISTRIBUTION/AVAILABILITY STATEMENT

Approved for public release; distribution unlimited

13. SUPPLEMENTARY NOTES

The original document contains color images.

14. ABSTRACT

15. SUBJECT TERMS

16. SECURITY CLASSIFICATION OF:

a. REPORT

unclassified b. ABSTRACT

unclassified c. THIS PAGE unclassified
17. LIMITATION OF ABSTRACT

\begin{tabular}{c|l}
$\begin{array}{c}\text { 18. NUMBER } \\
\text { OF PAGES } \\
7\end{array}$ & 19a. NAME OF \\
& \\
&
\end{tabular}


Within the CIC, the physical layout of the spaces is often not optimized for the organizational structure that exists. For example, in an AEGIS Cruiser CIC, the space is organized into basic command, anti-air warfare (AAW), and anti-surface/anti-submarine warfare (ASUW/ASW) groupings. However, each of these sub-teams sits facing away from each other and the leaders of these teams are not convenient to the command personnel. This layout is forced by the design of the display equipment.

Systematic, reliable methods are needed for the design of command centers-both the information space and the physical space-to best support the command team's organizational structure. Under Navy sponsorship, we have applied a comprehensive, systematic, quantitative methodology (Levchuk, Pattipati, \& Kleinman, 1998) to design a command center organization optimized for a typical mission for the Navy's next generation of surface combatants (Paley, Levchuk, Serfaty \& MacMillan, 1999). Because this Team Integrated Design Environment (TIDE) methodology produces a mission-driven specification of team roles and specifies in detail the interactions of the optimally structured team, the results can be used, in combination with practical design principles, to guide the design of shared information displays, communication networks, and physical lay-outs for command centers that best support future command teams.

\section{Approach}

Team modeling can provide powerful insights into the interactions and communication requirements between team members, and this has strong implications for the physical layout of the command space. For example, information that is displayed and acted on by a team of watchstanders is differentiated from information relevant only to individuals. This partitioning can be used to determine requirements for common displays and watchstander groupings. Alternatively, team modeling can help identify the impact of new technology on team layout. For example, a new volumetric display technology might provide a display area that is useful to several watchstanders simultaneously. As a result, these watchstanders could be physically moved in the command space to permit them to share and take full advantage of the new display.

Under the Navy's Manning Affordability Initiative (Cannon-Bowers, Bost, Hamburger, Crisp, Osga, and Perry, 1997), a number of innovative physical designs for command center layouts were developed. These Integrated Command Environment (ICE) designs specified possible future physical layouts and capabilities for shipboard command centers. We analyzed the suitability of several of these ICE designs for an optimally structured command team, and developed a matrix that identified team organizational design issues and possible physical implementations from the ICE designs to address them. This matrix is presented in Figure 1 and served as the basis for developing the physical design principles shown in Figure 2.

\section{Results}

Based on the defined principles, candidate physical layouts for alternative command center configurations can be designed based on shared information structures between the members of the command team. Figure 3 demonstrates a graphic version of the shared information structures across five decisions makers (DM1-DM5) in an optimized team structure. This figure is based on who needs access to the various information sources to complete their specified mission tasks. The model contains shared structures as well as private displays. For example, DM1, DM2 and 
Design Issues

- common information reference

- communication efficiency

- coordination efficiency private versus public
decision space

data distribution among DMs

efficiency of interface
Physical Implementation

\begin{tabular}{|l|l|}
\hline - shared displays \\
- shared display controls (e.g., zoom) \\
- joint information / data links
\end{tabular}

Figure 1. Team Design Issues and Physical Implications

(1) - physical proximity among DMs that is concomitant on (i) the information flow and (ii) decision coordination in the organization

- physical proximity of DM's decision support / control equipment (sensors, visual communication nets, control devices) that is concomitant on DM's functionality and his internal information flow

(3) allocation of private and public decision domains to DMs according to their responsibility distribution

(4) separating private from public workspaces to filter out the irrelevant information at critical time intervals

- segregating information acquisition control and information display features of radar / sensor equipment

- multi-functionality of decision support / control equipment (e.g., automated message generation)

7) - ergonomic design of decision support / control devices (MMWS)

(8) providing decision / control systems status monitoring capabilities to the superior DMs in the decision hierarchy

9 - monitoring the levels of DM thresholds (corresponding to different workload dimensions) to prevent failures due to overload

(10)

- control and display environment transfer from DM to DM

Figure 2. Model-Based Principles for Command Center Design 


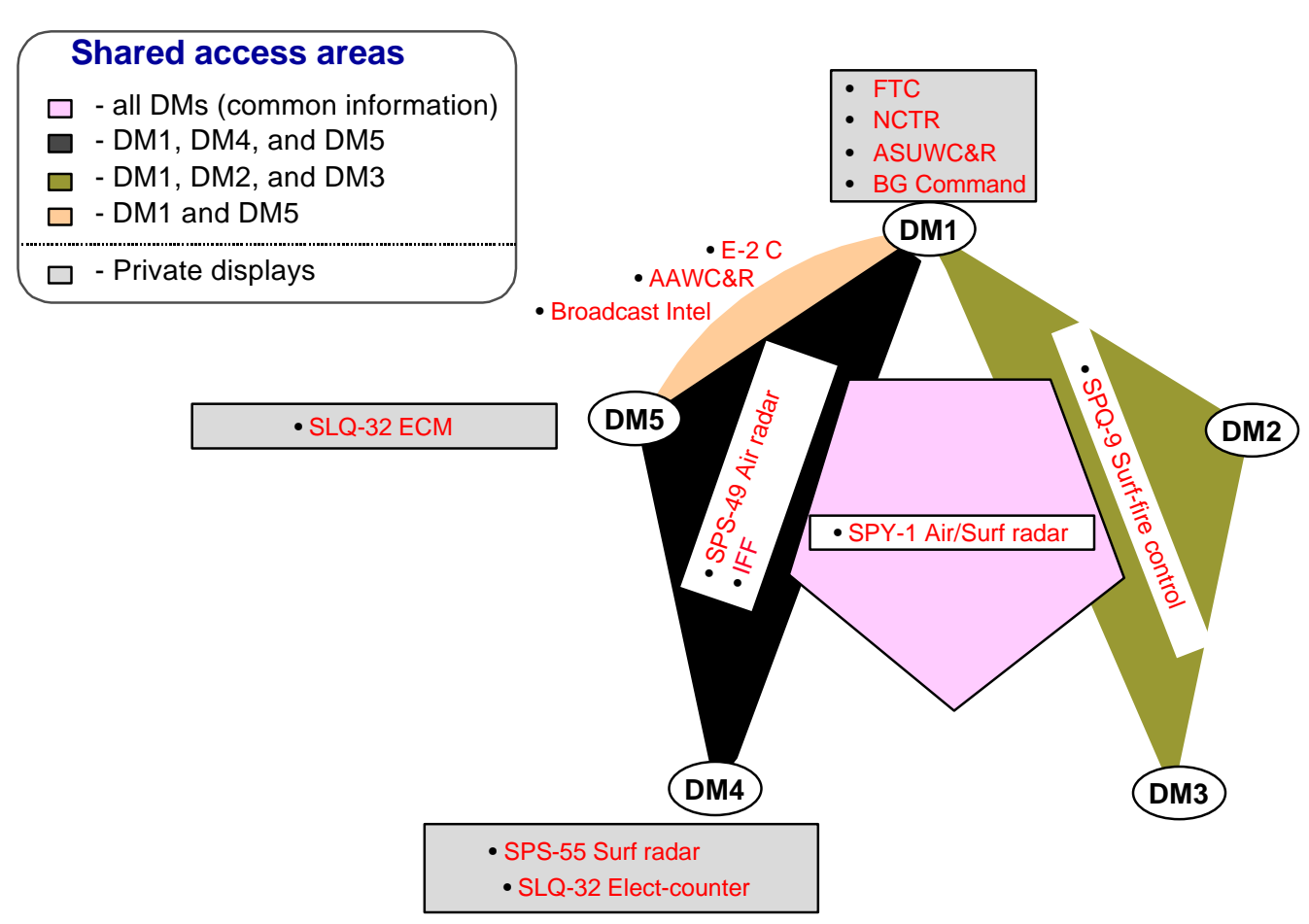

Figure 3. Information Access Structure for a Notional Command Team.

DM3 all must share data from the SPQ-9 radar and DM5 is the only team member with access to the SLQ-32 ECM. These access allocations are a direct output of the TIDE modeling process.

Based on these shared information structures, we are able to analyze the implications of team design parameters for the physical implementation of the command center, as instantiated in candidate physical layouts for alternative command center configurations. Information from the team modeling allowed us to comparatively assess the adequacy of various alternative physical command center configurations for supporting the five-person team design and information structure shown in Figure 3.

Figure 4 shows several "revolutionary" physical layouts developed for the Navy's SC-21 Science and Technology Manning Affordability Initiative program-a "boardroom design with tablebased displays and an "arena" design with an central display patterned after a sports arena.

Figure 5 presents an example of a physical layout based on the information access structure needed by the command team described in Figure 3, as implemented in the arena design of Figure 4. Based on the various information sources team members need to complete their specified mission tasks, and the within-team coordination, we can prescribe a physical layout, specifying shared information structures as well as private displays. This process can also be used to specify the contents of shared displays on the operators' workstations.

Based on the command-center design principles shown in Figure 2, we were able to evaluate the adequacy of each of the ICE designs for supporting the team and information structure shown in Figure 3. We were also able to develop an "optimal" design that combined some of the best features of the different ICE designs. 


\section{boardroom}

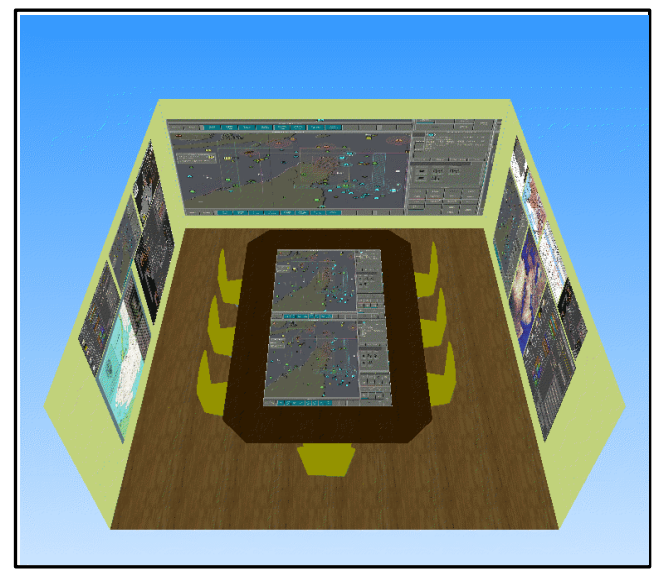

arena

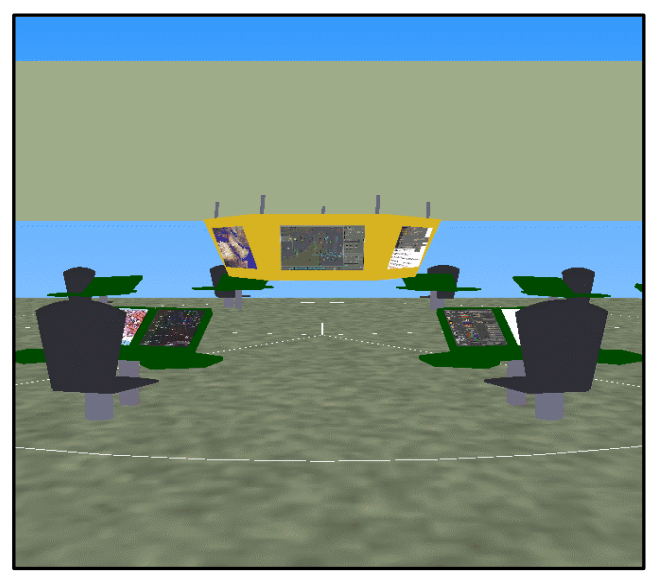

Figure 4. Examples of Integrated Command Environment (ICE) Designs

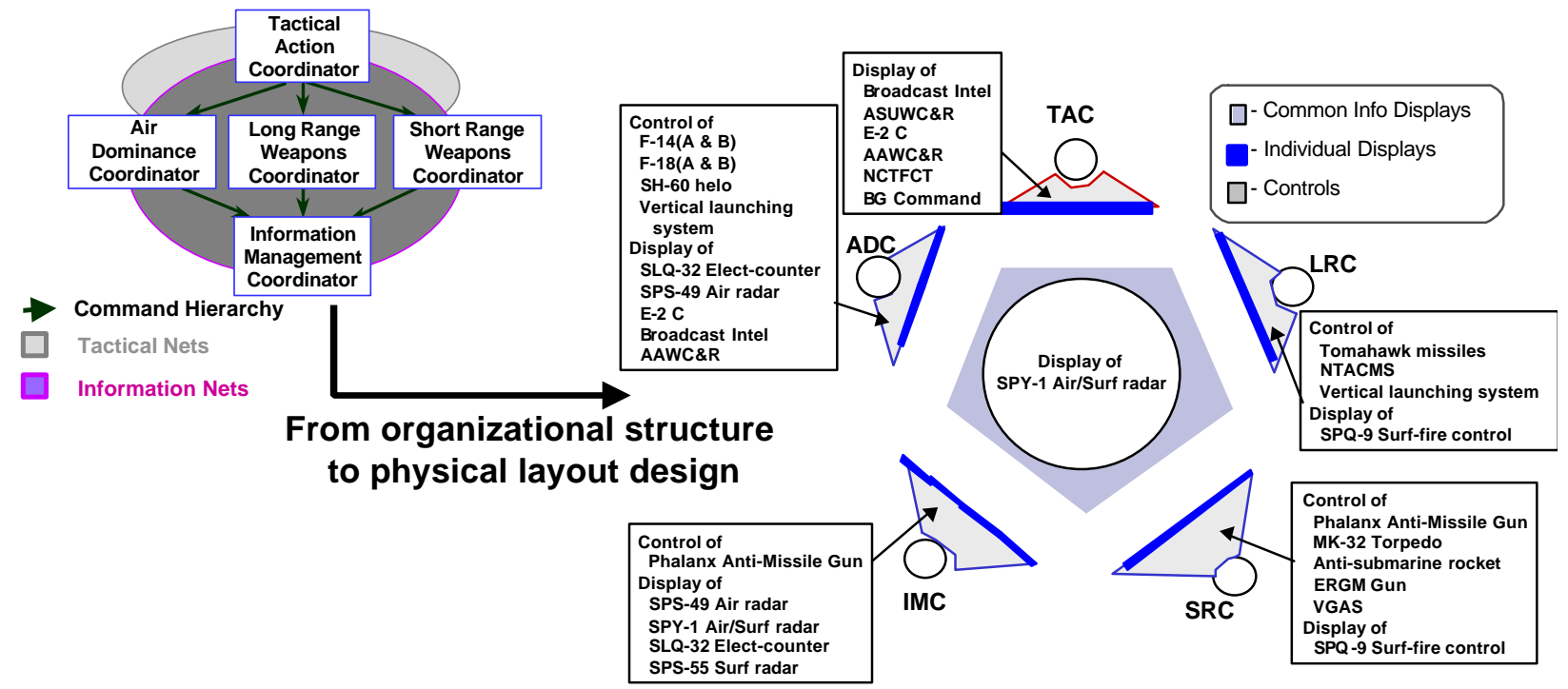

Figure 5. Physical Layouts for Arena Design Derived from Information Access, Command, and Communication Structures

This optimal design is shown in Figure 6. Figure 7 shows the results of a comparison between the boardroom design, the arena design, and the "optimal" design in meeting the principles listed in Figure 2. Although the team, as designed, could function in either the boardroom or the arena designs, we concluded that the somewhat different design of Figure 6 would be more congruent with the team's organizational and informational structure. At this point in our analysis, these comparisons are based on examination and judgment, but they are model-based and guided by design principles. 


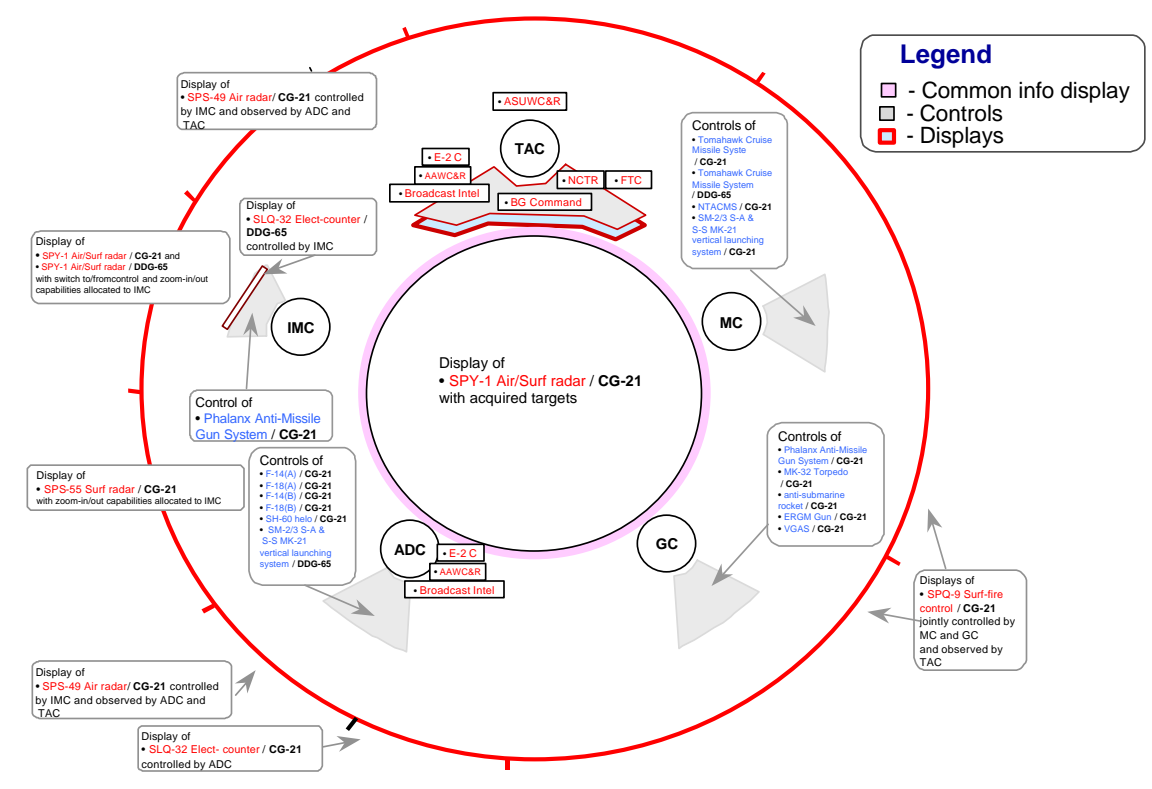

Figure 6. Optimized Physical Design for Command Team

\begin{tabular}{|c|c|c|c|c|}
\hline Design Principles & Implementation & boardroom & arena & Optimal \\
\hline \multirow{2}{*}{ - physical proximity among DMs } & - for information flow & + & - & + \\
\hline & - for decision coordination & + & - & + \\
\hline \multirow{2}{*}{ - physical proximity of equipment } & - of sensor displays & - & + & + \\
\hline & - of controls & + & + & + \\
\hline \multirow{2}{*}{$\begin{array}{l}\text { - allocation of private and public } \\
\text { domains }\end{array}$} & - in information distribution & + & + & + \\
\hline & - in control & + & + & + \\
\hline \multirow{2}{*}{$\begin{array}{l}\text { - separating private from public } \\
\text { workspaces }\end{array}$} & - isolation & - & + & + \\
\hline & - transformation from-into & - & - & + \\
\hline $\begin{array}{l}\text { - segregating control and display } \\
\text { features of equipment }\end{array}$ & $\begin{array}{l}\text { - eliminating zooming } \\
\text { interference }\end{array}$ & + & + & + \\
\hline - multi-functionality of equipment & - automatic message generation & - & feasible & feasible \\
\hline $\begin{array}{l}\text { (7) ergonomic design of control } \\
\text { devices }\end{array}$ & - visual control interface & feasible & feasible & feasible \\
\hline \multirow{2}{*}{ (8) - systems status monitoring } & - weapon-to-target map & feasible & feasible & feasible \\
\hline & - system status & + & + & + \\
\hline (9) - monitoring DM thresholds & - dynamic workload estimation & - & feasible & feasible \\
\hline \multirow[t]{2}{*}{ (10) $\cdot$ control and display transfer } & - controls & + & via reprogramming & + \\
\hline & - display environment transfer & + & $\begin{array}{l}\text { only with increased } \\
\text { information density }\end{array}$ & + \\
\hline
\end{tabular}

Figure 7. Comparison of Three Command Center Designs for Optimized Team 


\section{References}

Cannon-Bowers, J., Bost, R., Hamburger, T., Crisp, H., Osga, G., \& Perry, A. (1997). Achieving affordability through human system integration. Presented at the Third Annual Naval Aviation Systems Engineering Supportability Symposium, Arlington, VA.

Levchuk, Y., Pattipati, C., and Kleinman, D. (1998). Designing Adaptive Organizations to Process a Complex Mission: Algorithms and Applications. Proceedings of the 1998 Command and Control Research and Technology Symposium (11-32) Naval Postgraduate School, Monterey, CA.

Paley, M., Levchuk, Y.N., Serfaty, D. \& MacMillan, J. (1999). Designing Optimal Organizational Structures for Combat Information Centers in the Next Generation of Navy Ships. 1999 Command and Control Research and Technology Symposium. 